NASA Technical Memorandum 106324

\title{
Thermal History Effects on Electrical Relaxation and Conductivity for Potassium Silicate Glass With Low Alkali Concentrations
}

Paul W. Angel and Raiford E. Hann

Lewis Research Center

Cleveland, Ohio

and

Alfred R. Cooper

Case Western Reserve University

Cleveland, Ohio

August 1993 



\title{
THERMAL HISTORY EFFECTS ON ELECTRICAL RELAXATION AND CONDUCTIVITY FOR
}

\section{POTASSIUM SILICATE GLASS WITH LOW ALKALI CONCENTRATIONS}

\author{
Paul W. Angel and Raiford E. Hann \\ National Aeronautics and Space Administration \\ Lewis Research Center \\ Cleveland, Ohio 44135 \\ and \\ Alfred R. Cooper \\ Department of Materials Science and Engineering \\ Case Western Reserve University \\ Cleveland, Ohio 44106
}

\section{SUMMARY}

Electrical response measurements from $10 \mathrm{~Hz}$ to $100 \mathrm{kHz}$ between 120 and $540{ }^{\circ} \mathrm{C}$ were made on potassium-silicate glasses with alkali oxide contents of $2,3,5$, and $10 \mathrm{~mol} \%$. Low alkali content glasses were chosen in order to try to reduce the Coulombic interactions between alkali ions to the point that frozen structural effects from the glass could be observed. Conductivity and electrical relaxation responses for both annealed and quenched glasses of the same composition were compared. Lower DC conductivity $\left(\sigma_{\mathrm{DC}}\right)$ activation energies were measured for the quenched compared to the annealed glasses. The two glasses with the lowest alkali contents exhibited a non-Arrhenius concave up curvature in the $\log \sigma_{\mathrm{DC}}$ against $1 / \mathrm{T}$ plots, which decreased upon quenching. A sharp decrease in $\sigma_{\mathrm{DC}}$ was observed for glasses containing $\mathrm{K}_{2} \mathrm{O}$ concentrations of $5 \mathrm{~mol} \%$ or less. The log modulus loss peak ( $\left.\mathrm{M}^{\prime \prime}\right)$ maximum frequency plots against 1/T all showed Arrhenius behavior for both annealed and quenched samples. The activation energies for these plots closely agreed with the $\sigma_{\mathrm{DC}}$ activation energies. A sharp increase in activation energy was observed for both series as the potassium oxide concentration decreased. Changes in the electrical response are attributed to structural effects due to different alkali concentrations. Differences between the annealed and quenched response are linked to a change in the distribution of activation energies (DAE).

\section{INTRODUCTION}

A great deal of interest has been expressed recently in developing a fast ion conductor material to act as an electrode for molten salt fuel cell applications (ref. 1). A better understanding of the ionic diffusion in disordered solids and the electric relaxation or dispersion of the permittivity as a function of frequency is necessary to aid in this type of research. One way to provide some insight into the conduction mechanism associated with these materials is to study the AC behavior of simple binary systems such as alkalisilicate glasses.

Theories used to describe electrical relaxation may be categorized as either systems that exhibit timedependent transition rates (TDTR) for charge carrier migration from site to site in the solid (refs. 2 and 3) or those based on a distribution of transition rates (DTR) which characterize charge carrier transport on a disordered potential energy surface (refs. 4 to 7). Theories based on the TDTR are assumed to arise from Coulombic interactions occurring between migrating charge carriers. Since the charge carriers can only move cooperatively, a perturbation such as an applied step field would be followed by correlated motion of carriers that is progressively damped yielding the time dependency (ref. 2). In comparison, 
theories based on a DTR have been shown, through the use of a continuous time random walk (CTRW) approximation (ref. 8), to result in a frequency dependent conductivity, $\sigma(\omega)$, where $\omega$ is the angular frequency. The $\sigma(\omega)$ is related to a distribution of activation energies (DAE) which results in a distribution of relaxation times (DRT) given by $g(\tau)$ (refs. 7,9 , and 10). Both theories correctly predict the frequency response of the real portion of the conductivity, $\sigma(\omega)^{\prime}$, characterized by an approximate power law behavior (ref. 7):

$$
\sigma(\omega)^{\prime}=\sigma_{\mathrm{DC}}+\mathbf{A} \omega^{\mathbf{n}}
$$

where $\sigma_{\mathrm{DC}}$ is the $\mathrm{DC}$ conductivity, $\mathrm{A}$ is constant and $\mathrm{n}$ is the slope of the frequency dependent portion of the curve having a value within the interval $0<\mathrm{n} \leq 1$.

By increasing the charge carrier interionic distances through the use of low alkali content glass systems, one may decrease the Coulombic interaction between charge carriers which is assumed to yield the TDTR. The observed AC response should then be dominated by the DAE for conduction resulting from the disordered potential energy surface. By measuring the $\mathrm{AC}$ response of quenched samples after their annealed AC properties have been measured, the effects of structural changes within the glass, which potentially may alter the DAE, can be observed without changing the glass composition. A similar study on the AC response of both annealed and quenched binary silicate glasses by Boesch and Moynihan (ref. 11) focused on both a potassium and sodium-silicate glass, but at alkali contents of $\mathbf{3 0} \mathbf{m o l} \%$. Yoshiyagawa (ref. 12), and Yoshiyagawa and Tomozawa (ref. 13) also examined annealed and quenched lithium-silicate glasses with alkali concentrations between 30 to $60 \mathrm{~mol} \%$. Both studies found little change in the AC properties upon quenching. By only focusing on glasses with high alkali concentrations, any potential change in the DAE may have been over shadowed by Coulombic interactions between the alkali ions.

Kelly et al. (ref. 14) have shown that the Haven ratio for a sodium-silicate glass does not start to approach unity until alkali concentrations drop below $5 \mathrm{~mol} \%$. In relating correlation effects to the theory of irreversible thermodynamics, the Haven ratio, $H_{R}$, may be written as (refs. 15 and 16):

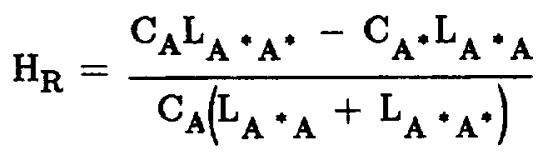

where $C_{A}$ and $C_{A^{*}}$ are the concentrations of host and tracer ions respectively and $L_{i j}$ are the Onsager coefficients. For the condition, $C_{A} \rightarrow C_{A^{*}} \rightarrow 0$, the off-diagonal coefficients, $L_{A^{*}}$, approach zero since the interaction between the host flux and the tracer flux diminishes. As a result of these dilute conditions, $\mathrm{H}_{\mathrm{R}}$ approaches unity. This indicates that the resulting electrical conductivity may be related to the charge carrier mobility of a dilute system with negligible interionic Coulombic and blocking interactions. The remaining serial correlation effects may be attributed to the disordered topology of the potential energy landscape associated with the rigid silicon-oxygen network. The effective elimination of the interionic interaction effects should allow the experimenter to probe this potential energy landscape by way of electrical relaxation measurements such as impedance spectroscopy. In addition, if the dilute system characterized by $\mathrm{H}_{\mathrm{R}}=1$ is accepted as an approximation of a single particle system, all correlation may be considered to be self-serial correlation effects (ref. 17). This condition now provides experimental access to the elusive geometrical correlation factor, $f$, which may be given by:

$$
f=\frac{\sigma(0)}{\sigma(\infty)}
$$


where $\sigma(0)$ and $\sigma(\infty)$ are the DC and high-frequency limiting conductivities, respectively. Data from Kelly et al. (ref. 14) suggest that alkali concentrations must be $<5 \mathrm{~mol} \%$ before the Coulombic interactions of the alkali begin to decrease to the point that the potential energy surface due to the glass structure begins to dominate the conduction process.

Calculations by Martin (ref. 18) on alkali ion-ion separation distances show that ions begin to no longer occupy adjacent interstitial positions at concentrations of $<7 \mathrm{~mol} \%$, which is in agreement with Kelly's work on Haven ratios (ref. 14). By concentrating on glasses with alkali concentration of less then $10 \mathrm{~mol} \%$, it may be possible to induce changes in the DAE enough to affect the AC response. In addition, only a small amount of $\mathrm{AC}$ response data on low alkali silicate glasses currently exists. The purpose of this initial study was to investigate AC conductivity and complex modulus behavior over a wide temperature and frequency range for potassium-silicate glasses with alkali concentrations from 2 to $10 \mathrm{~mol} \%$.

\section{EXPERIMENTAL PROCEDURE}

\section{Sample Preparation}

Glasses were prepared in $30 \mathrm{~g}$ batches using 99.99 percent pure potassium carbonate ${ }^{*}$ and ground silica $^{* *}$. Binary compositions of the system $\mathrm{xK}_{2} \mathrm{O}-(100-\mathrm{x}) \mathrm{SiO}_{2}$ where $\mathrm{x}$ was equal to $2,3,5$, and $10 \mathrm{~mol} \%$. Herein, the specific compositions will be referred to as $x \mathrm{KS}$ where KS corresponds to potassium-silicate and ' $x$ ' corresponds to the concentration of potassium oxide in mole percent in the glass. Each batch was dry mixed to increase homogeneity and then calcined at $950^{\circ} \mathrm{C}$ for $4 \mathrm{hr}$ in a platinum-3 percent rhodium crucible. The calcined powder was then ball milled for $3 \mathrm{hr}$ to -325 mesh powder in porcelain jars using alumina media to further homogenize the batch before melting. Glasses were then melted in the same platinum-3 percent rhodium crucibles using a molybdenum-disilicide furnace between 1550 and $1670^{\circ} \mathrm{C}$. Glass batches were held at temperature for up to $24 \mathrm{hr}$ to minimize bubbles before roughly annealing at $550{ }^{\circ} \mathrm{C}$. The 2 and $3 \mathrm{~mol} \% \mathrm{~K}_{2} \mathrm{O}$ samples still contained bubbles of $0.5 \mathrm{~mm}$ in diameter or less after this time, which corresponded to less than 1 vol\%. Given the slow rate of fining at $1670{ }^{\circ} \mathrm{C}$ for these compositions and the potential volatilization of the alkali, all of the glasses were removed after $24 \mathrm{hr}$ of melting. Chemical analysis using a plasma analysis technique was used to confirm potassium concentrations and to determine the level of any contaminates, including alumina, soda, and lithia. Alumina concentrations never exceeded $0.1 \mathrm{~mol} \%$ while alkali contaminates were in the ppm level. Table I summarizes the potassium oxide results.

Low alkali content silicate glasses have been reported to phase separate given the appropriate conditions and follow the trend of lithia being the most susceptible and cesium being the least susceptible (i.e., $\mathrm{Li}>\mathrm{Na}>\mathrm{K}>\mathrm{Rb}>\mathrm{Cs}$ ) (ref. 19). Examination of glass samples with back scattered electron (BSE) and electron-microprobe analysis showed no evidence of phase separation for these compositions. All glass samples were stored in a vacuum desiccator after annealing to reduce water absorption.

Samples for electrical measurements were obtained by coring samples from the crucibles using a 5/8-in. diamond coring bit. Cylindrical samples of $1.2 \mathrm{~cm}$ in length were obtained using this technique. Cored samples then underwent a final annealing cycle, an example of which is shown in figure 1. Approximate annealing temperatures were chosen based on published viscosity data for potassium silicate glasses (ref. 20). Disks with parallel faces were cut from the annealed cores using a diamond wafering saw. The

*Aldrich Chemical Company, Inc., Milwaukee, WI 53233.

${ }^{* *}$ Fisher Scientific, Fair Lawn, NJ 07410. 
faces of the samples were then polished with $600 \mathrm{grit} \mathrm{SiC}$ before platinum electrodes were sputtered in a two electrode configuration. Kerosene or lapping oil was used in place of water whenever possible during all stages of sample preparation to minimize any leaching of the alkali from the samples.

Quenched samples were prepared from annealed samples that had completed comprehensive impedance analysis. This eliminated the possibility of other factors (e.g., sample size) from contributing to dissimilarities in the measured data between samples with different thermal histories. The platinum electrode material was first removed with 600 grit SiC before the sample was placed into a furnace at $800^{\circ} \mathrm{C}$. After $20 \mathrm{~min}$, the sample was quickly removed, placed on tabular alumina and allow to air cool to room temperature. Examination of the sample after quenching under polarized light showed a typical birefringence pattern for a quenched glass. After repolishing on 600 grit SiC, platinum electrodes were reapplied.

Density measurements were made on both annealed and quenched specimens using the Archimedes technique. Again, lapping oil was used in place of water to reduce alkali leaching. The values, reported in Table I, have a relative precision of $\pm 0.002 \mathrm{~g} / \mathrm{cm}^{3}$.

\section{Impedance Measurements}

Impedance measurements were made using a Schlumberger SL1260 Impedance/Gain Phase Analyzer between $10 \mathrm{~Hz}$ and $100 \mathrm{kHz}$ in the temperature range of 120 to $550^{\circ} \mathrm{C}$, as applicable. Fifty points per decade were taken for each sample during which a null file, created at $200^{\circ} \mathrm{C}$, was used to remove any contributions from the measurement system from the total response. All measurements were made using a 2-V test signal and a 1-sec time delay between successive points. A 3-sec time integration was used for each point to minimize measurement error. Test specimens were placed in an Inconel cell with spring loaded platinum electrodes and leads. Circular Inconel shields placed near the sample diminished any induced effects from the electrical windings in the furnace. A Pt-Pt10Rh thermocouple, placed adjacent to the specimen, was used for all sample temperature measurements. The test cell was positioned inside a mullite tube that was open at one end and located inside a clam-shell furnace. A dry $\mathrm{N}_{2}$ atmosphere was used to ensure the integrity of the electrodes and to reduce water absorption by the specimen.

Given the measured complex impedance, the complex modulus $\mathrm{M}^{*}$ and admittance $\mathrm{Y}^{*}$ can be calculated from the equations (ref. 21):

$$
\begin{gathered}
Y^{*}=Y^{\prime}-i Y^{\prime \prime}=\frac{1}{Z^{*}} \\
M^{*}=M^{\prime}-i M^{\prime \prime}=i \omega Z^{*} \varepsilon_{0} G
\end{gathered}
$$

where $i$ is equal to $\sqrt{-1}, \varepsilon_{0}$ is the permittivity of free space and $G$, the geometric factor, is equal to the area of the electrode surface's divide by the sample thickness $(A / L)$. The real portion of the $A C$ conductivity is the real part of the admittance divide by the geometric factor. It is thus very simple to switch from one immittance level to another, keeping in mind that it is still the same data just being viewed at a different level. Since each immittance level has some drawbacks (e.g., $M^{*}$ plots tend to suppress low frequency information while $Z^{*}$ suppresses high frequency information) it is generally best to examine the data at several different levels. 
Multiple experiments were conducted to confirm the repeatability of the AC properties as determined by this experimental procedure. Several samples with thicknesses between 0.85 and $1.75 \mathrm{~mm}$ were cut from the same glass core and measured with negligible differences. Duplicate samples from different glass batches were also compared with similar results. Finally, a glass sample was purposely prepared that had a high concentration of bubbles. The measured properties of this sample was then compared to a bubble free sample to verify that the bubbles have negligible effect on the AC properties of the glasses. Summary admittance and modulus plots of several of these samples are given in figure 2.

By using sputtered platinum electrodes, polishing the sample surfaces to 600 grit and using a small test signal, no electrode polarization effects were observed except for the 10KS sample at higher temperatures. The onset of electrode polarization can easily be determined by an almost exponential increase in the capacitance data at low frequencies. Data points believed to include electrode polarization effects were discarded from the data sets.

\section{RESULTS}

\section{Conductivity}

The real part of the admittance curves all exhibit the form of the response typical of other alkali silicate glasses (refs. 10 to 13). Examples of the real portion of typical conductivity plots are shown in figure 3 for the $3 \mathrm{KS}$ quenched and annealed glass at three different temperatures. At low frequencies the admittance is frequency independent while at higher frequencies it follows an approximate power law type of behavior. This type of response, characteristic of ionic conductors (refs. 10 to 13, and 22), can be represented by the equation (1). By extrapolating the frequency independent portion of the admittance curves, the $\sigma_{\mathrm{DC}}$ may be calculated. Figure 4 shows the $\log \sigma_{\mathrm{DC}}$ plotted against $1 / \mathrm{T}$ for both the quenched and annealed glasses while figure 5 shows all the annealed data on a single plot. These types of plots are based on the Arrhenius equation (ref. 23):

$$
\sigma_{\mathrm{DC}}=\mathrm{A} \exp ^{-\mathrm{E}_{\mathrm{o}} / \mathrm{RT}}
$$

where $A$ is a constant, $E_{a}$ is the activation energy for $\sigma_{D C}, R$ is the ideal gas constant, and $T$ is the absolute temperature. For the annealed glasses, both the $5 \mathrm{KS}$ and $10 \mathrm{KS}$ compositions closely follow an Arrhenius type behavior while the two lower alkali content glasses display slight concave up curvatures in the lower temperature region. The degree of curvature appears to increase as a function of both decreasing temperature and alkali content. A small amount of upward curvature in $\log \sigma_{\mathrm{DC}}$ versus $1 / \mathrm{T}$ plots has been reported previously (ref. 10). Upon quenching, all of the plots for the four glass compositions shifted to higher conductivity values with the magnitude of the shift increasing with increasing alkali concentration. In addition, the degree of curvature in the $2 \mathrm{KS}$ and $3 \mathrm{KS}$ plots decreased slightly.

By plotting the $\log \sigma_{\mathrm{DC}}$ as a function of potassium content, as shown in figure 6(a), two different approximately linear regions are observed. The $\sigma_{\mathrm{DC}}$ changes very rapidly with increasing potassium oxide content up to approximately 7 to $10 \mathrm{~mol} \%$, at which point a much lower rate of increase occurs. This change in slope appears to occur over a relatively short range of alkali content. Data from work by other authors (refs. 11, and 24 to 29) are also shown in figure 6(a) and demonstrate good agreement with this investigation. 


\section{Complex Modulus}

The imaginary part of the modulus as a function of frequency at two different temperatures is shown in figure 7 for the $2 \mathrm{KS}$ and $10 \mathrm{KS}$ samples, quenched and annealed. All plots exhibit the characteristic increase in $M^{\prime}$ as a function of frequency and the occurrence of a loss peak in the $M^{\prime \prime}$ data, commonly referred to as conductivity relaxation peak (refs. 11 and 23). The plots for the imaginary part of the electrical modulus against $\log$ frequency exhibit a maximum at $\omega \tau_{0}=1$, where $\tau_{0}$ corresponds to the reciprocal of the frequency at the modulus loss peak maximum. The shape of the loss peak is very broad compared to electrical relaxation peaks produced by materials with a single relaxation time or Debye response (ref. 11). These type of broad loss peaks have been attributed to a distribution of relaxation times (refs. 7, 11, and 22). The loss peaks are all asymmetric with the same skewing towards the high frequency end of the spectrum. The modulus loss peak has been previously found to follow an Arrhenius behavior similar to that followed by $\sigma_{\mathrm{DC}}$ based on the equation:

$$
M^{\prime \prime}(\omega)=M_{o}^{\prime \prime} \exp ^{-E_{a}^{*} / R T}
$$

Plots of the $\log$ modulus loss peak maximum as a function of $1 / T$, given in figure 8 , all follow Arrhenius behavior, even for the two lower alkali content glasses. This is in contrast to the upward curvature observed in the $\log \sigma_{\mathrm{DC}}$ versus $1 / \mathrm{T}$ plots for the $2 \mathrm{KS}$ and $3 \mathrm{KS}$ plots. Also similar to the $\log \sigma_{\mathrm{DC}}$ versus $1 / \mathrm{T}$ plots, a slightly larger gap between the annealed and quenched lines is observed for the higher alkali content glasses compared to the lower alkali content glass.

\section{$\sigma_{\mathrm{DC}}$ and $\mathrm{M}^{\prime \prime}$ Peak Activation Energies}

Activation energies from both the annealed and quenched plots for the $\sigma_{\mathrm{DC}}$ and $\mathrm{M}^{\prime \prime}$ plots $( \pm 0.75 \mathrm{Kcal} / \mathrm{mol})$, shown in figure $9(\mathrm{a})$ as a function of alkali content, exhibit close agreement when comparing values for $\sigma_{\mathrm{DC}}$ against $\mathrm{M}^{\prime \prime}$ for either the annealed or quenched samples. However, when comparing annealed against quenched activation energies for either $\sigma_{\mathrm{DC}}$ or $\mathrm{M}^{\prime \prime}$, the quenched terms were observed to be approximately $2.5 \mathrm{Kcal} /$ mole lower than the annealed terms. The magnitude of the decrease in the activation energies upon quenching appears to be independent of the alkali concentration.

Figure $9(\mathrm{a})$ also shows that the activation energy for $\sigma_{\mathrm{DC}}$ is larger for the lower alkali content glasses and decreases almost linearly for increasing alkali concentrations up to the value for the $5 \mathrm{KS}$ sample, at which point the slope decreases. In figure 9(b), activation energy values for an expanded range of alkali concentrations from other authors (refs. 24, 27, and 30) are included and show good agreement with this study.

\section{Glass Density}

Density values for the annealed glasses all closely agreed with values from previous authors (refs. 24 to 26). Quenching resulted in a 1-percent decrease in the measured density, on average. Slightly smaller changes in density were measured for the lower alkali content glasses in comparison to the higher alkali content glasses. 


\section{DISCUSSION}

The upward shift in the $\log \sigma_{\mathrm{DC}}$ and $\mathrm{M}^{\prime \prime}$ plots as a function of $1 / \mathrm{T}$ upon quenching is the result of the pre-exponential term from the two Arrhenius equations (eqs. (6) and (7), respectively) increasing. The magnitude of the shifts as a function of alkali concentration can be linked to the glass transition temperature, $T_{g}$, for the different compositions. The $T_{g}$ decreases as the alkali content of the glasses increases which results in a larger $\Delta \mathrm{T}$, which is given by:

$$
\Delta \mathrm{T}=\mathrm{T}_{\text {quench }}-\mathrm{T}_{\mathrm{g}}
$$

These increasing $\Delta T$ 's as a function of increasing alkali concentration cause larger structural differences between the annealed and quenched glasses for the higher alkali content glasses when compared to the lower alkali content glasses.

In similar studies by Boesch and Moynihan (ref. 11) and by Yoshiyagawa and Tomozawa (ref. 13) investigating high alkali content $(\approx 30 \mathrm{~mol} \%)$ silicate glasses with different thermal histories, the only observed change in the $\log \sigma_{\mathrm{DC}}$ versus $1 / \mathrm{T}$ plots was an analogous increase in the pre-exponential term upon quenching. No change in the shape or slope of the quenched curves in comparison to the annealed curves was observed. For the 2KS and 3KS glasses studied here, quenching decreased the amount of nonArrhenian curvature measurably above that observed for the annealed plots when compared over the same temperature range.

Given that the admittance curves at these low temperatures have just reached the frequency independent region, it may be argued that $\sigma(\omega)$ is still decreasing with frequency. If this is correct, it is not possible to extrapolate the curves without getting an erroneously high value for $\sigma_{\mathrm{DC}}$. However for all the points measured, the modulus loss peak, which has previously been linked to the onset of the frequency independent portion of the admittance curve (ref. 23), has already occurred. As a precaution, all $\sigma_{\mathrm{DC}}$ values were verified by using a least squares arc fit on the complex impedance plots, an example of which is shown in figure 10. Most circular fits were similar to the one depicted in figure 10 in that the intercept on the real axis, which represents the resistivity, agreed with the extrapolated values. Some of the complex impedance plots at the lower temperatures deviated from semicircles when the real part of the impedance increased at a greater rate than the imaginary part at low frequencies. This resulted in a small tail on the low frequency end of the semicircle plots and resulted in slightly lower $\sigma_{\mathrm{DC}}$ values to be reported. Generally the error fell within temperature measurement deviations and was less than the size of the data points on the plots given in figure 4. For the cases where the difference in $\sigma_{\mathrm{DC}}$ was larger than any error introduced by small temperature deviations, the $\sigma_{\mathrm{DC}}$ point was replaced by values from the least squares semicircle fits.

One potential explanation for the curvature observed in the $2 \mathrm{KS}$ and $3 \mathrm{KS} \log \sigma_{\mathrm{DC}}$ plots is based upon some recent Monte Carlo simulations in diffusion (ref. 31) in which a Gaussian distribution for saddle point energies combined with a single stable point or site energy was used to calculate the diffusion coefficient, D. It was found that the Gaussian distribution for the saddle point energies resulted in higher than expected diffusion coefficients at lower temperatures. This resulted in a concave up curvature in the $\log \mathrm{D}$ against $1 / T$ plot, very similar to the curvature observed in figure 4 . When similar distributions were used for both saddle point and stable point energies, Arrhenius behavior was observed and was due to a compensation effect between the saddle and site energy distributions. This suggests that at higher alkali concentrations, the saddle and stable point energies have very similar distributions. As the alkali content decreases, the Coulombic interactions between the alkali diminish and the potential energy surface is now dominated by the frozen structure. The reduced Coulombic interactions from neighboring alkali ions 
could potentially change the distribution of either the saddle or stable point energies resulting in the observed curvature for the $\log \sigma_{\mathrm{DC}}$ plot. Since changing the thermal history of a glass is known to have structural effects, quenching could further change the statistical landscape of the potential energy surface. The larger resulting deviation between saddle and stable point energy distributions could then generate the observed changes in the curvature.

Another possible explanation for the curvature in the $\sigma_{\mathrm{DC}}$ Arrhenius plot is that the pre-exponential term and/or the activation energy term in equation (1) is temperature dependent. Work by Syed et al. (ref. 32) has suggested that any temperature dependency of the pre-exponential term is very weak and that it is best that $\sigma_{\mathrm{DC}}$ data be fit to the Arrhenius equation with no temperature dependency in the preexponential term. A temperature dependency of the activation energy term would imply that some type of structural change is occurring in the glass. This type of change would be more likely to manifest itself in the higher temperature portion of the $\sigma_{\mathrm{DC}}$ plot rather than the observed low temperature region. However, changes in bond angles and other similar structural alterations commonly associated with thermal expansion could potentially give the activation energy term a temperature dependency.

The sudden change in slope for the $\sigma_{\mathrm{DC}}$ plotted against potassium oxide content occurs in the same alkali concentration region that Kelly et al. (ref. 14) showed that the Haven ration began to approach unity. The change in the two plots at coinciding alkali concentrations suggests that the approximately 5 to $7 \mathrm{~mol} \%$ alkali concentration for potassium-silicate glasses corresponds to the point where the diffusing alkali begin to impede each other. For alkali concentrations greater than 7 mol\%, occupation of available nearest neighbor site begins to increase. In order for an alkali to jump to a new site, a nearest neighbor alkali atom may also have to jump to open an adjacent site. Due to the high site occupancy, the probability of an alkali jumping back to its original site is also much higher. As a result, the $\sigma_{\mathrm{DC}}$ increases at a slower rate as the portion of alkali ions contributing to $\sigma_{\mathrm{DC}}$ decreases. This behavior is related to the ionic transport phenomena associated with the conductivity correlation factor (ref. 34), $\mathrm{f}_{\mathrm{I}}$, which reflects serial correlation effects of the entire system. For alkali concentrations greater than 5 to $7 \mathrm{~mol} \%$, the percolation efficiency of all charge carriers is apparently reduced due to their collective interaction resulting in a reduction of the net flux of charge carriers.

As the alkali concentration decreases below $7 \mathrm{~mol} \%$, the distance between nearest neighbor alkali ions increases. However, the lower alkali concentrations also result in fewer nonbridging oxygen atoms (NBO) and additional glass defects that aid in the conduction process by creating more open glass structures. The number of percolation paths through the glass also decreases while the average energy on each path increases as indicated by the higher $\sigma_{\mathrm{DC}}$ values for $2 \mathrm{KS}$ and $3 \mathrm{KS}$. As a result, the activation energy increases while $\sigma_{\mathrm{DC}}$ sharply decreases as the charge carrier mobility decreases. This type of interpretation is consistent with the decrease in Haven ratio as a function of alkali content measured for alkali-silicate glasses by Kelly et al. (ref. 14).

\section{SUMMARY OF CONCLUSIONS}

Initial findings indicate that both the $\sigma_{\mathrm{DC}}$ and $\mathrm{M}^{\prime \prime}$ activation energies vary as a function of thermal history for glasses with low potassium oxide concentrations. The non-Arrhenius behavior observed for $\sigma_{\mathrm{DC}}$ for the $2 \mathrm{KS}$ and $3 \mathrm{KS}$ glasses may be linked to changes in the DAE. The sharp decrease in $\sigma_{\mathrm{DC}}$ with decreasing potassium content is believed to be due to the increasing distance between NBO and other defects in the glass structure which results in fewer percolation paths for conduction. 


\section{REFERENCES}

1. Levasseur, A.; Kbala, M.; Hagenmuller, P.; Couturier, G.; and Dunto, Y.: "Elaboration and Characterization of Lithium Conducting Thin Film Glasses, Solid State Ion., 9-10 [2] pp. 1439-1444 (1983).

2. Jonscher, A.K.: "Review: A New Understanding of the Dielectric Relaxation of Solids," J. Matl. Sc., 16, pp. 2037-2060 (1981).

3. Ngai, K.L.; and White, C.T.: "Frequency Dependence of Dielectric Loss in Condensed Matter," Phys. Rev. B, 20 [6] pp. 2475-2486 (1979).

4. Macdonald, J.R.: “Generalizations of 'Universal Dielectric Response' and a General Distribution-ofActivation-Energies Model for Dielectric and Conducting Systems," J. Appl. Phys. 58 [5] pp. 1971-1978 (1985).

5. Macdonald, J.R.: "Linear Relaxation: Distributions, Thermal Activation, Structure and Ambiguity," J. Appl. Phys. 62 [11] pp. R51-62 (1987).

6. Macdonald, J.R.: “Analysis of AC Conduction in Disordered Solids,” J. Appl. Phys. 65 [12] pp. 4845-4853 (1989).

7. Dyre, J.C.: "The Random Free-Energy Barrier Model for AC Conduction in Disordered Solids," J. Appl. Phys. 64 [5] pp. 2456-2468 (1988).

8. Scher, H.; and Lax, M.: "Stochastic Transport in a Disordered Solid. I. Theory," Phys. Rev. B, 7 [10] pp. 4491-4502 (1973).

9. Abelard, P.; and Baumard, J.F.: "Study of the DC and AC Electrical Properties of an YttriaStabilized Zirconia Single Crystal $\left.\left[\left(\mathrm{ZrO}_{2}\right)_{0.88}-\left(\mathrm{Y}_{2} \mathrm{O}_{3}\right)_{0.12}\right)\right]$, " Phys. Rev. B, $26[2]$ pp. 1005-1017 (1982).

10. Niklasson, G.A.: “Comparison of Dielectric Response Functions for Conducting Materials," J. Appl. Phys., 66 [9] pp. 4350-4359 (1989).

11. Boesch, L.P.; and Moynihan, C.T.: "Effect of Thermal History on Conductivity and Electrical Relaxation in Alkali Silicate Glasses,” J. Non-Cryst. Solids 17, pp. 44-60 (1975).

12. Yoshiyagawa, M.: “Electrical Properties of Rapidly Quenched Alkali-Silicate Glasses," Masters Thesis, Rensselaer Polytechnic Inst., 1982.

13. Yoshiyagawa, M.; and Tomozawa, M.: "Electrical Properties of Rapidly Quenched Lithium-Silicate Glasses," J. De Physique, Colloque C9, supplement au n ${ }^{\circ} 12$, Tome 43, pp. C9-411 to C9-414, (1982). 
14. Kelly III, J.E.; Cordaro, J.F.; and Tomozawa, M.: "Correlations Effects on Alkali Diffusion in Binary Alkali Oxide Glasses,” J. of Non-Cryst. Solids, 41, pp. 47-55 (1980).

15. Murch, G.E.: “The Haven Ratio in Fast Ion Conductors," Solid State Ionics, 7, pp. 177-198 (1982).

16. Dyre, J.C.; and Murch, G.E.: "Correlation Effects in Tracer Diffusion and Ionic Conductivity II," Solid State Ionics, 21, pp. 139-142 (1986).

17. Cooper, A.R.: "Coupling, Cross Terms, Correlation and Conduction," pp. 57-74 Mass Transport Phenomena in Ceramics, Materials Science Research, Vol. 9, Edited by A.R. Cooper and A.H. Heur, Plenum Press, New York, 1974.

18. Martin, S.W.: "Conductivity Relaxation in Glass: Compositional Contributions to Non-Exponentiality," Appl. Phys. A 49, pp. 239-247 (1989).

19. Charles, R.J.: “The Origin of Immiscibility in Silicate Solutions," Phys. Chem. Glasses, 10 [5] pp. 169-178 (1969).

20. Bansal, N.P.; and Doremus, R.H.: Handbook of Glass Properties, Academic Press, New York, 1986.

21. Macdonald, J.R.: Impedance Spectroscopy: Emphasizing Solid Materials and Systems, John Wiley \& Sons, New York, 1987.

22. Mott, N.F.; and Davis, E.A.: Electronic Processes in Non-Crystalline Materials, 2nd ed. (Clarendon, Oxford, 1979).

23. Tomozawa, M.; Cordaro, J.; and Singh, M.: “Low Frequency Dielectric Relaxation from Complex Impedance and Complex Electrical 'Modulus'," J. Mater. Sci. 14 [8] pp. 1945-1951 (1979).

24. Charles, R.J.: J. Am. Ceram. Soc., 49, p. 55 (1966).

25. Otto, K.; and Milberg, M.E.: "Ionic Conduction in Alkali and Thallium Silicate Glasses," J. Am. Ceram. Soc., 51, p. 326 (1968).

26. Namikawa, H.: J. Non-Cryst Solids, 18, p. 173 (1975).

27. Ravaine; Diard, J.P.; and Souquet, J.L.: "Dielectric Relaxation in Alkali Metal Oxide Conductive Glasses Studied by Complex Impedance Measurements," J.C.S. Faraday II 71, p. 1935 (1975).

28. Evstrop'ev, K.K.; and Pavlovskii, V.K.: "Ionic Diffusion and Electroconductivity of Single-Alkaline Glasses," Inorg. Mater (Engl. Transl.) 3, p. 592 (1967).

29. Kingery, W.D.; Bowen, H.K.; and Uhlmann, D.R.: Introduction to Ceramics, John Wiley \& Sons, New York, 1976. 
30. Hakim, R.M.; and Uhlmann, D.R.: “Electrical Conductivity of Alkali Silicate Glasses," Phys. Chem. Glasses, 12 [5] pp. 132-138 (1971).

31. Limoge, Y.; and Bocquet, J.L.: "Monte Carlo Simulation in Diffusion Studies: Time Scale Problems," Acta Metal., 36 [7] pp. 1717-1722 (1988).

32. Syed, R.; Gavin, D.L.; and Moynihan, C.T.: J. Am. Ceram. Soc., 8, p. C-129 (1982).

33. Murch, G.E.; and Dyre, J.C.: "Correlation Effects in Ionic Conductivity," CRC Critical Reviews in Solid State and Materials Sciences, 15, pp. 345-365 (1989).

TABLE I.-ALKALI CONCENTRATION
\begin{tabular}{|c|c|c|c|c|}
\hline Glass composition & $2 \mathrm{KS}$ & $3 \mathrm{KS}$ & $5 \mathrm{KS}$ & $10 \mathrm{KS}$ \\
\hline $\begin{array}{c}\text { Potassium oxide concentration } \\
( \pm 0.5 \mathrm{~mol} \%)\end{array}$ & 1.7 & 2.8 & 4.4 & 9.4 \\
$\begin{array}{c}\text { Annealed density } \\
\left( \pm 0.002 \mathrm{~g} / \mathrm{cm}^{3}\right) \\
\begin{array}{c}\text { Quenched density } \\
\left( \pm 0.002 \mathrm{~g} / \mathrm{cm}^{3}\right)\end{array}\end{array}$ & 2.223 & 2.234 & 2.258 & 2.307 \\
\hline
\end{tabular}

-Trace elements were all less than 100 ppm, including all other alkali. 


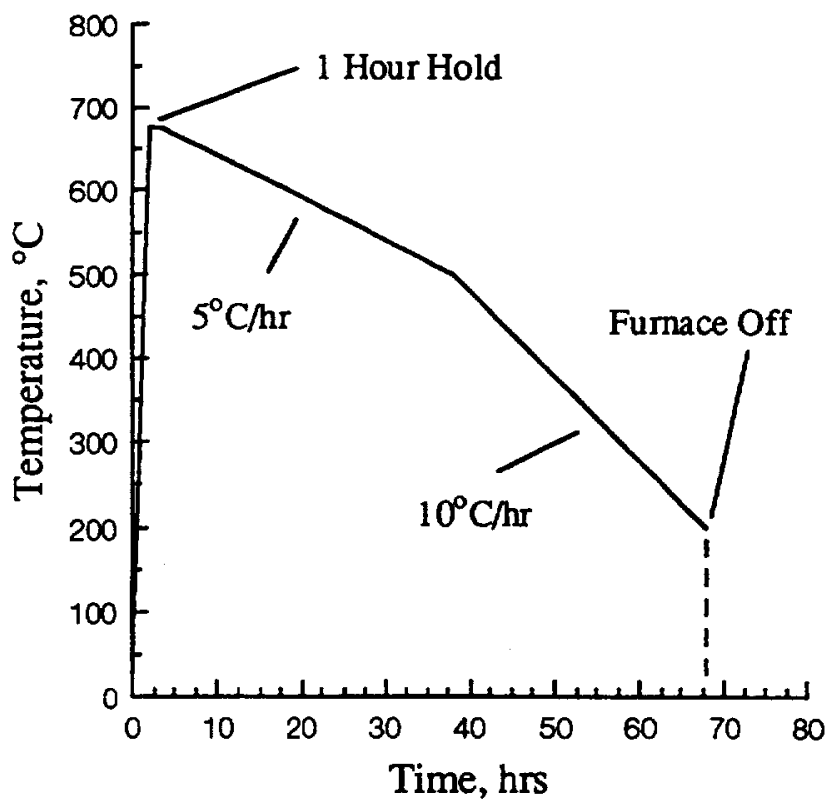

Figure 1.-Typical annealing schedule used before preparing samples for electrical measurements. A $675^{\circ} \mathrm{C}$ hold was used for the 2KS and $3 \mathrm{KS}$ samples, a $650^{\circ} \mathrm{C}$ hold for the $5 \mathrm{KS}$ and a $625^{\circ} \mathrm{C}$ hold for the 10KS samples. 


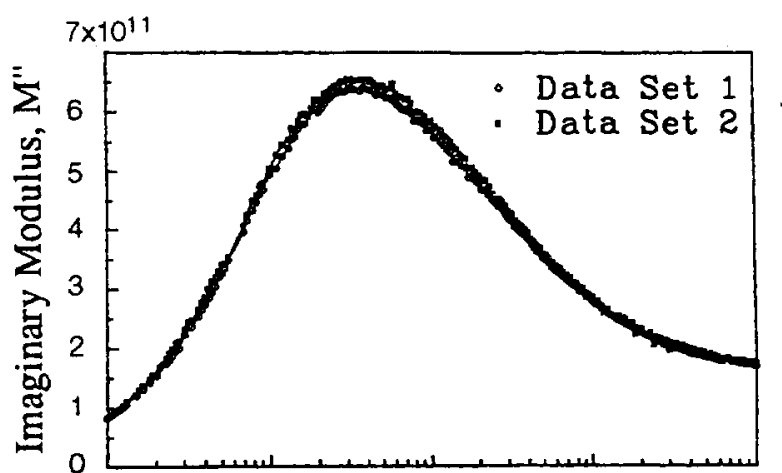

(a) Imaginary modulus plot for $2 \mathrm{KS}$ annealed sample at $472{ }^{\circ} \mathrm{C}$ measured 24 hours apart. The sample was removed from the measurement device and repositioned between measurements.

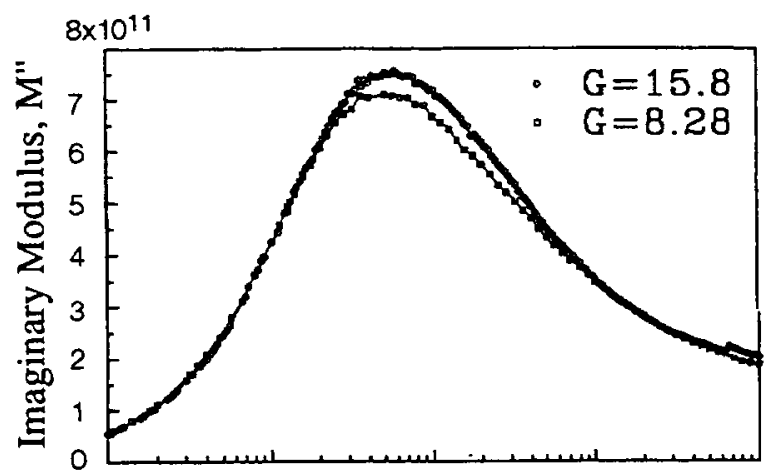

(b) Imaginary modulus plot for $2 \mathrm{KS}$ samples from the same glass core but with different thickness ( 1.67 and $1.88 \mathrm{~mm}$ ) which resulted in the different geometric values, $G$ ( 15.8 and 8.28 respectively).

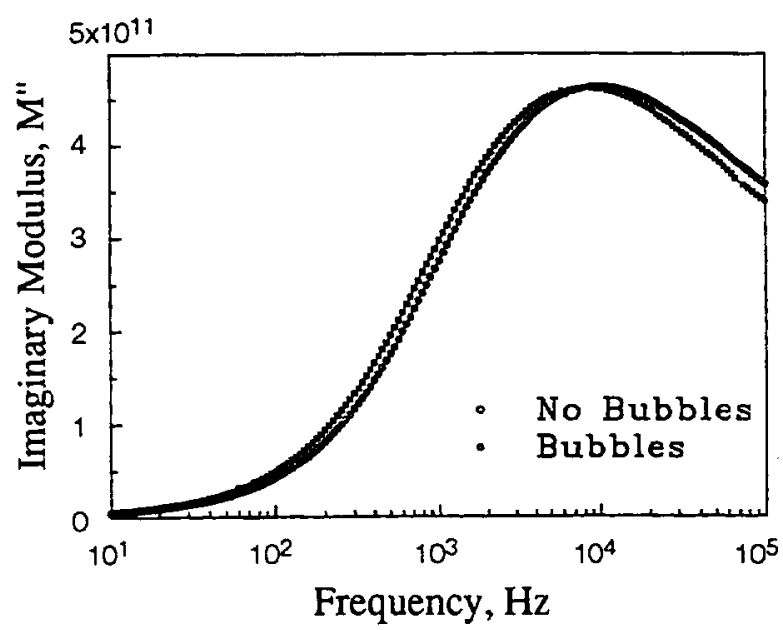

Figure 2c.-Imaginary modulus plot for two $5 \mathrm{KS}$ glasses both at $368^{\circ} \mathrm{C}$. The first samples is free of all bubbles while the second contains a small fraction $<1$ vol\% of the same size observed in the 2KS and 3KS samples. The small shift in the maximum loss peak Irequency is likely due to small compositional differences between the two glasses.

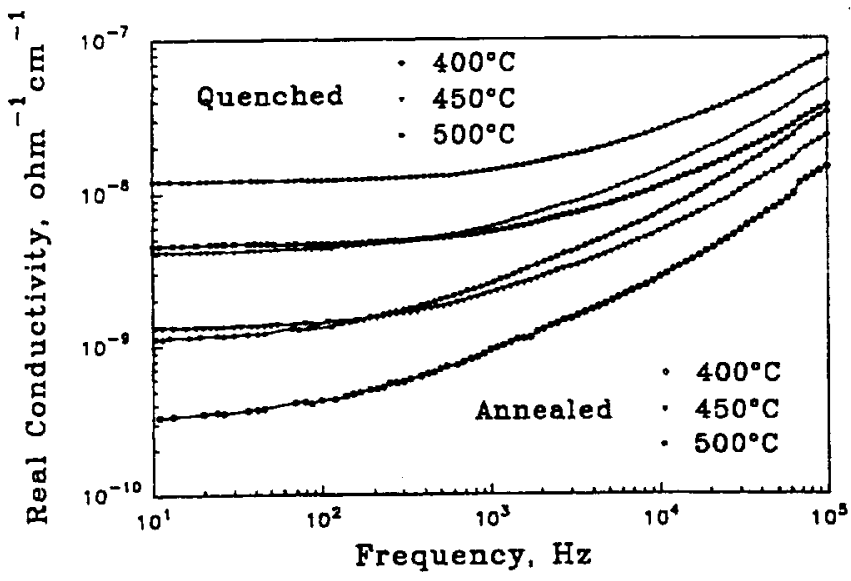

Figure 3.- Log of the real part of the conductivity against frequency for the $3 \mathrm{KS}$ annealed and quenched glasses at three temperatures. 


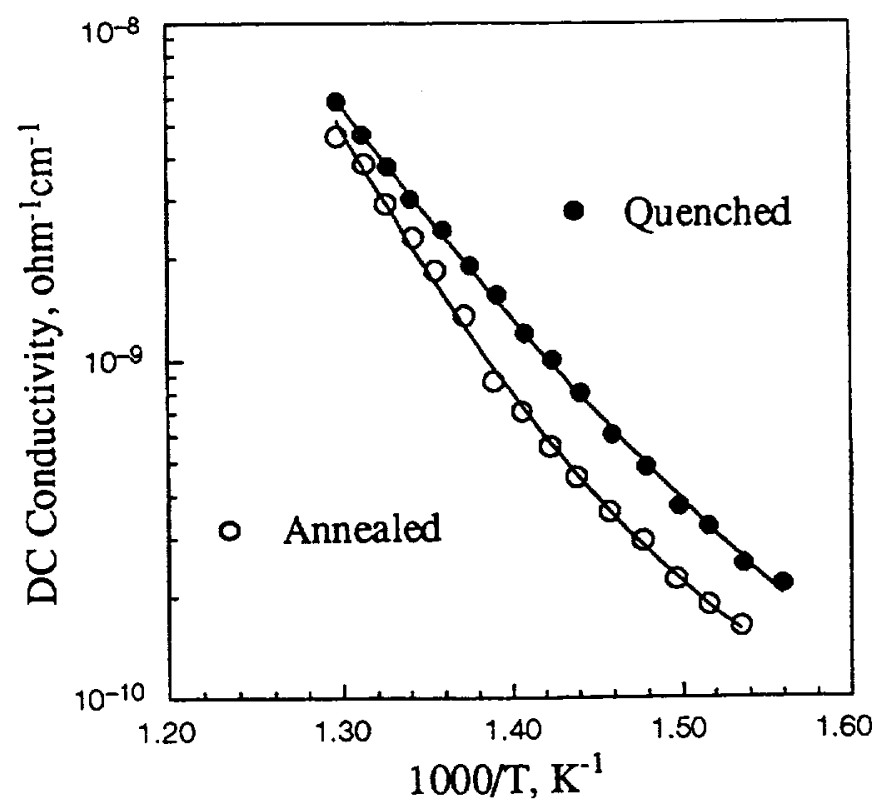

(a) $2 \mathrm{KS}$.

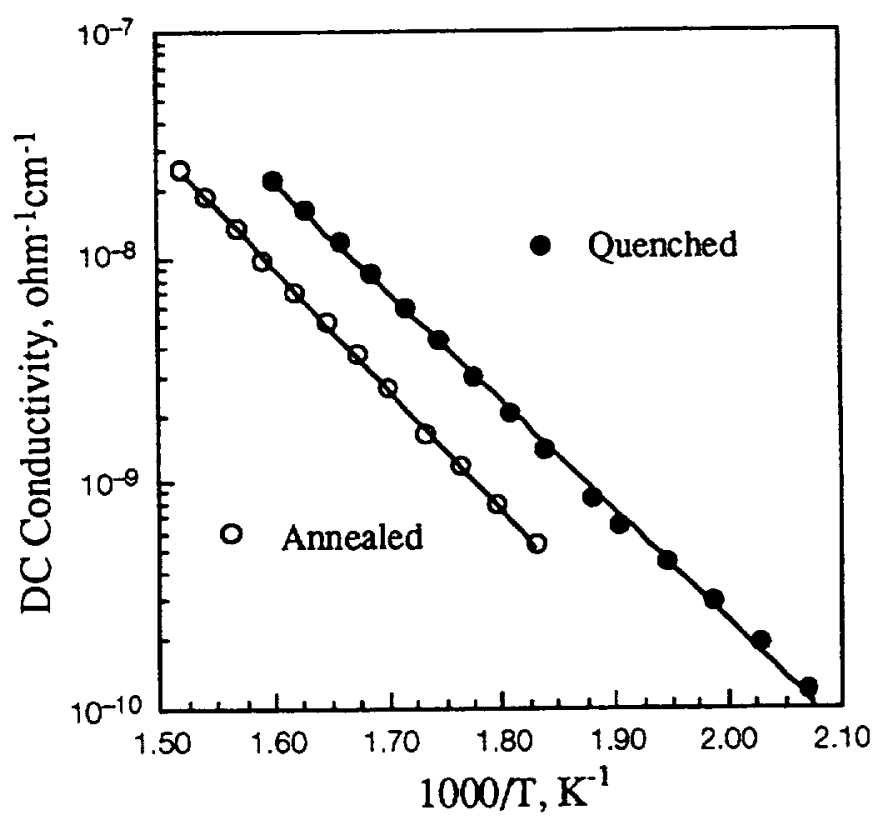

(c) $5 \mathrm{KS}$.

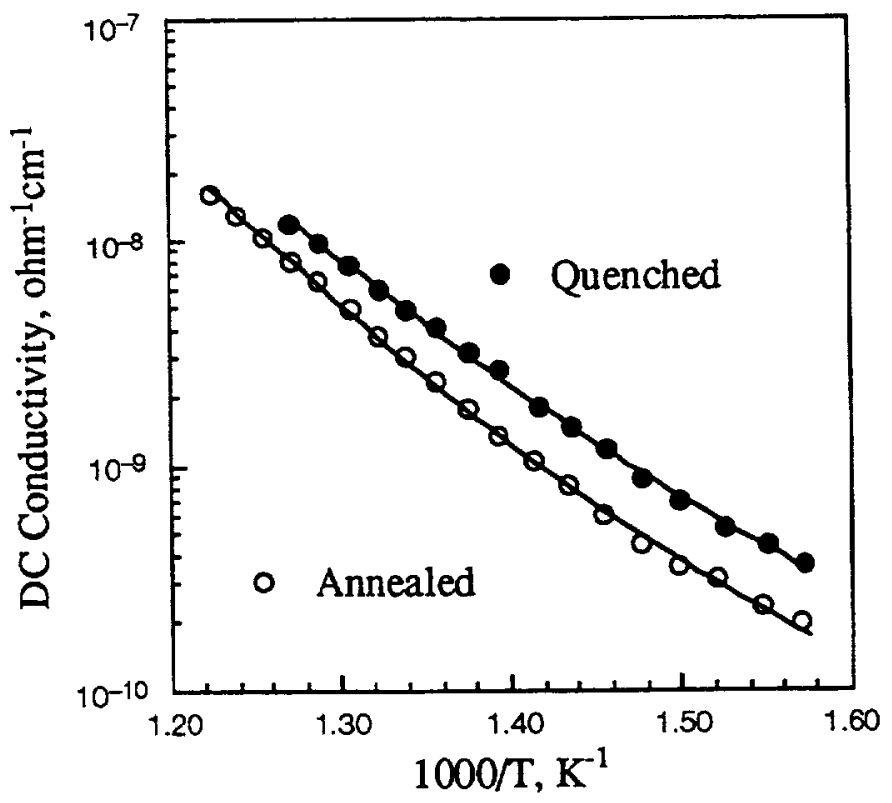

(b) 3KS.

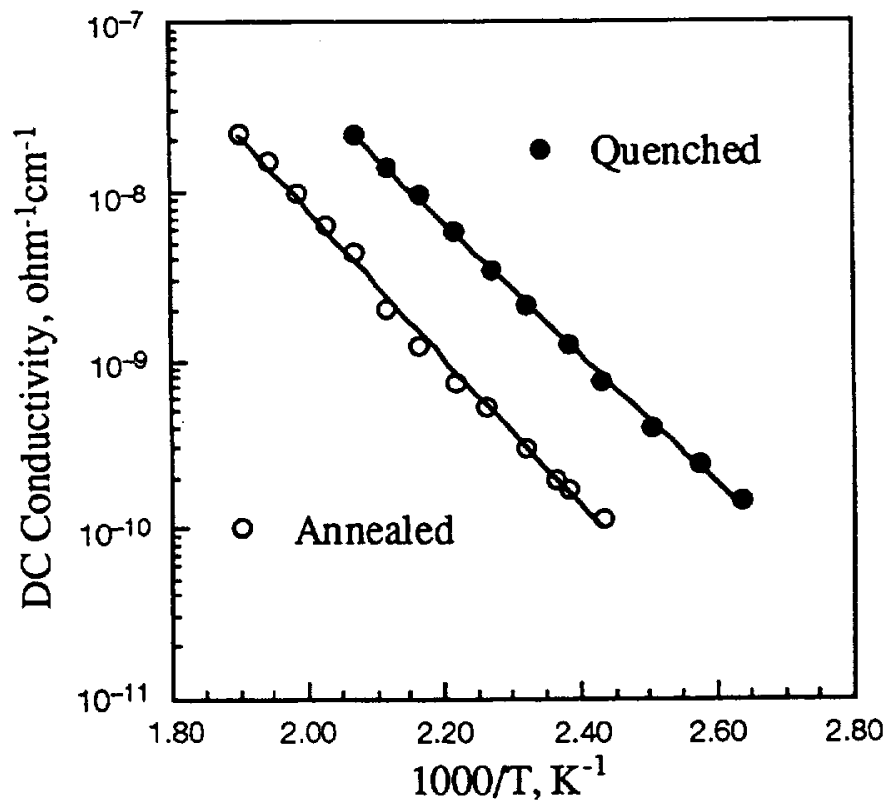

(d) 10KS.

Figure 4. - $\log$ of $\sigma_{\mathrm{DC}}$ against $1 / \mathrm{T}$ for both annealed and quenched glass samples. 


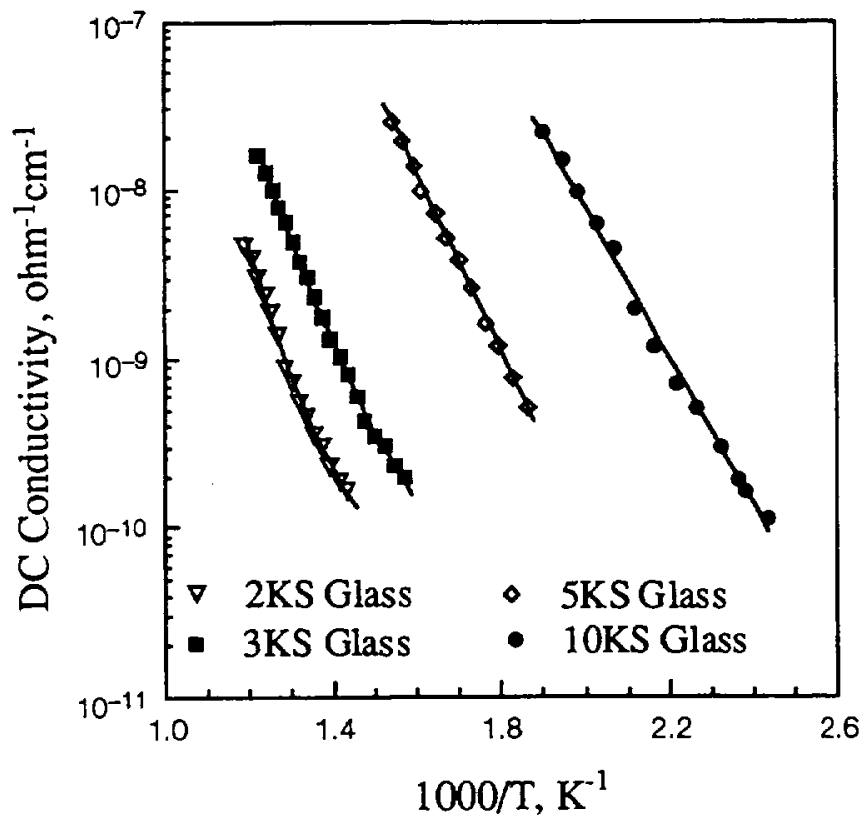

Figure 5.- Log of $\sigma_{D C}$ against $1 \pi$ for all four annealed glasses. While the change in slope is small for each data set, a large change in the pre-exponential term " $A$ " from equation (1) results in a large difference between the $3 K S$ and $5 K S$ glasses.

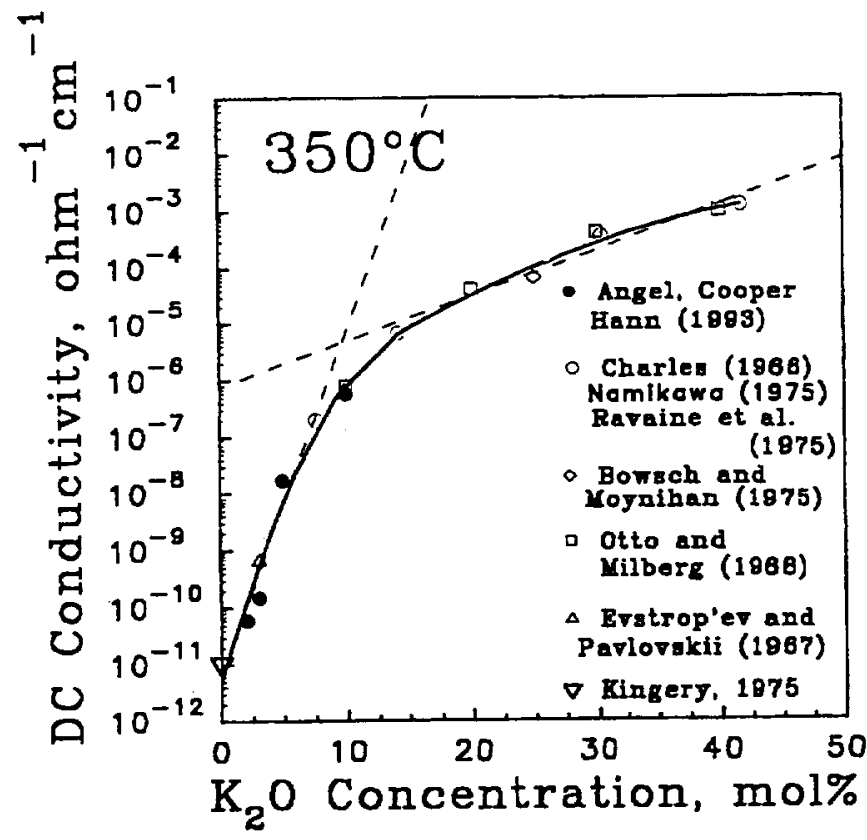

Figure 6. - $\log$ of the $D C$ conductivity as a function of the potassium oxide concentration. The dashed lines are extrapolated from the two linear regions of the curves. The intercept of the two lines corresponds to approximately $7 \mathrm{~mol} \% \mathrm{~K}_{2} \mathrm{O}$. 


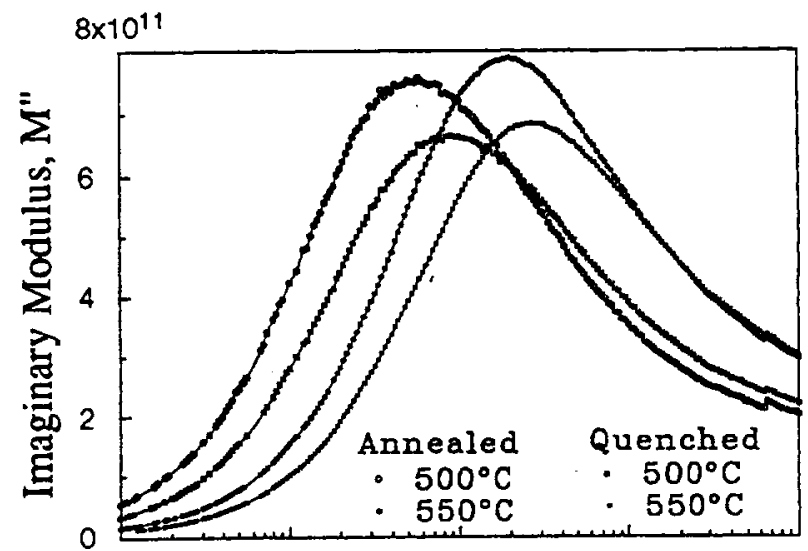

(a) $2 \mathrm{KS}$.

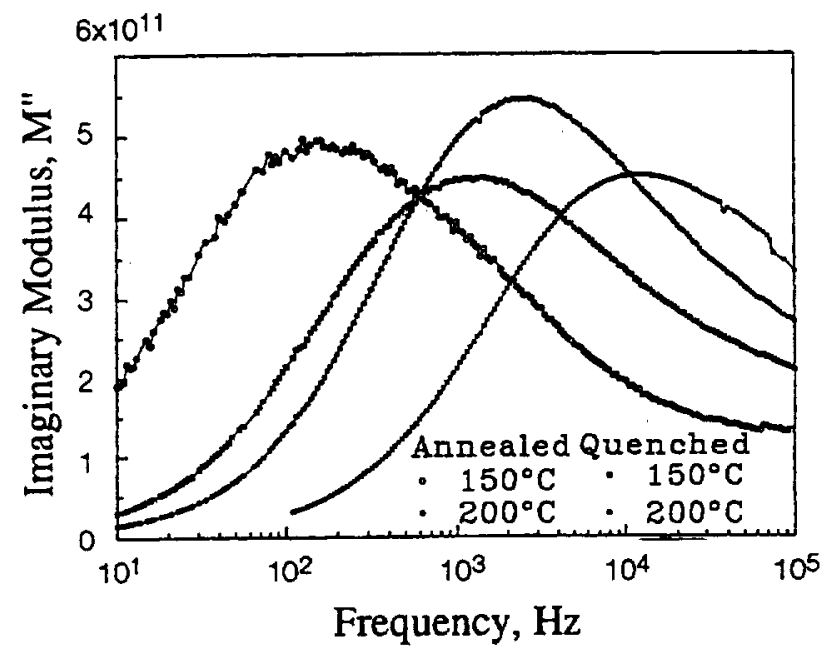

(b) 10KS.

Figure 7.-Complex modulus curves for the annealed and quenched samples at two different temperatures. 


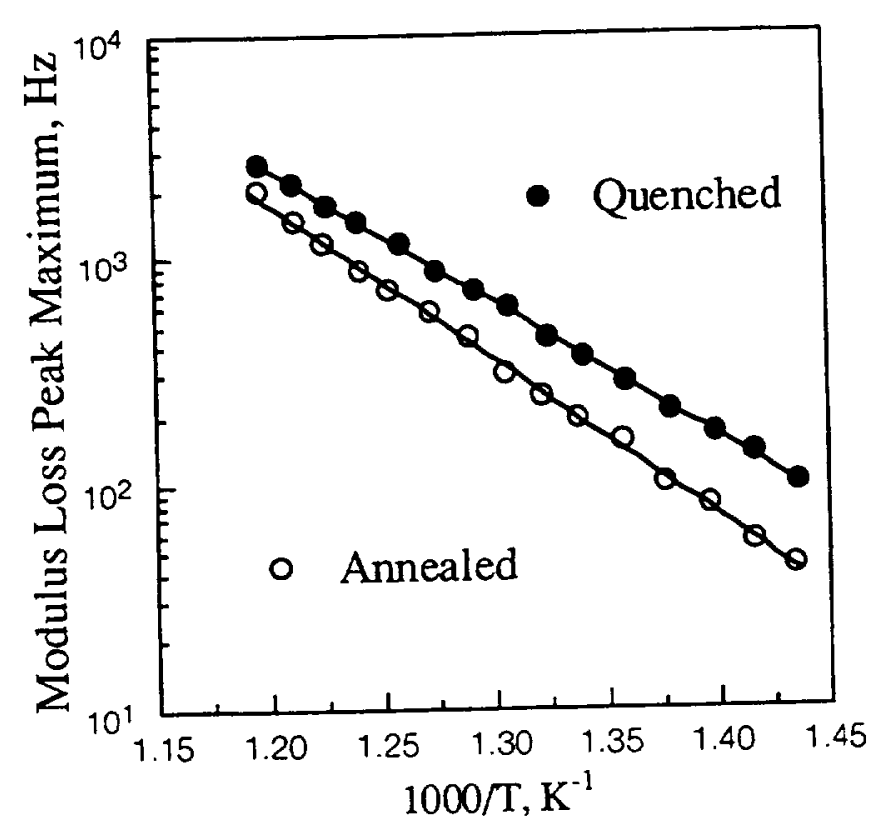

(a) 2KS.

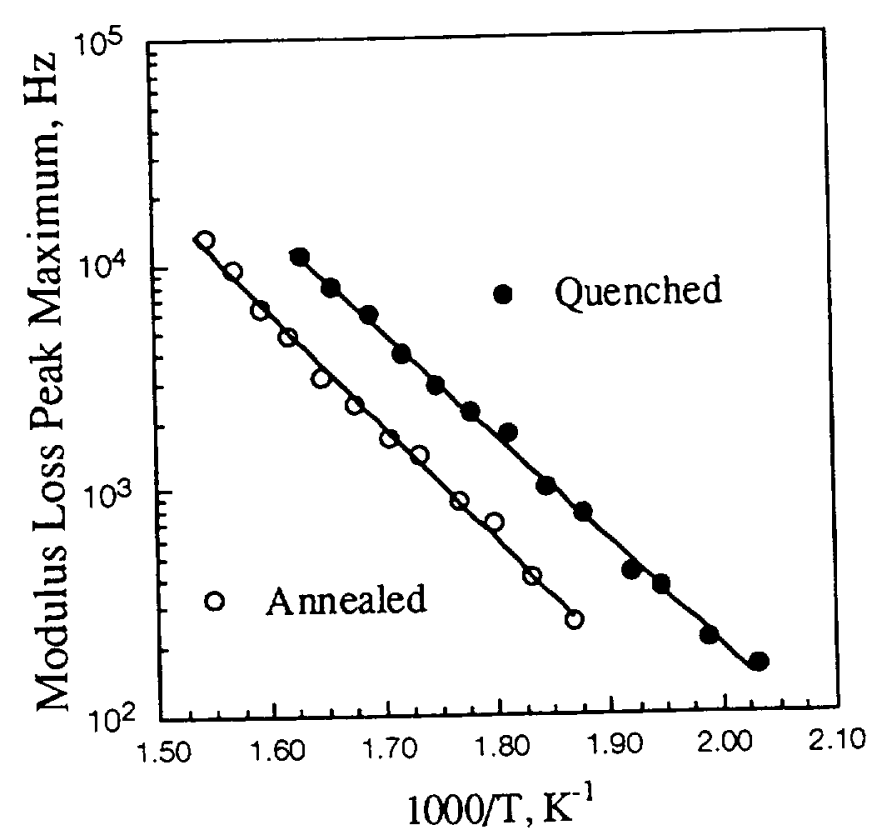

(c) $5 \mathrm{KS}$.

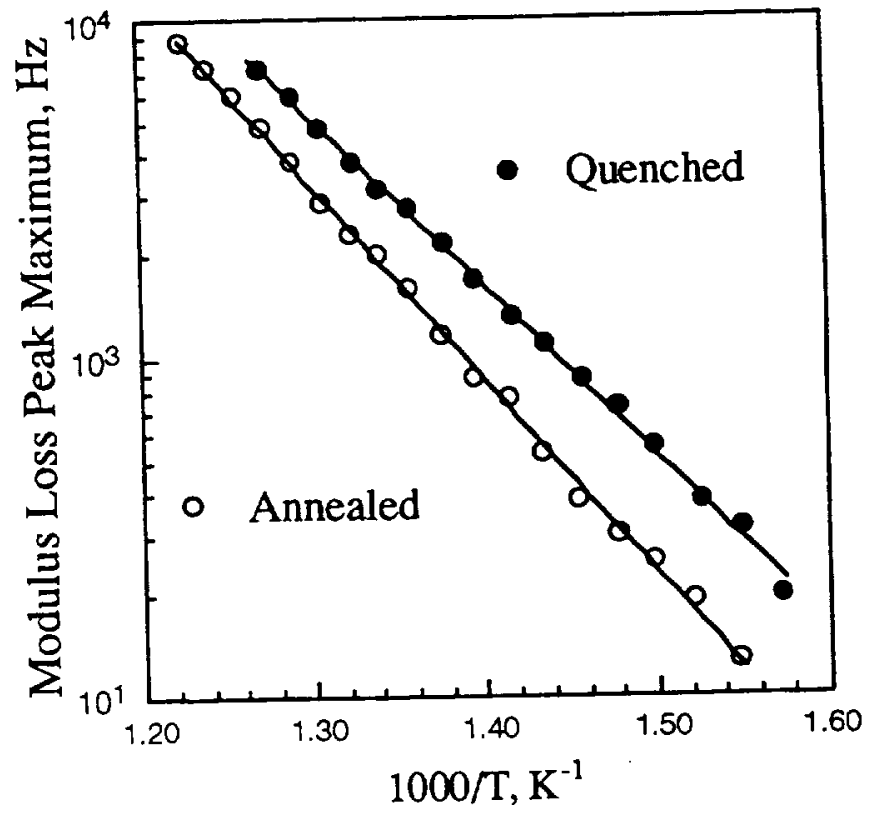

(b) 3 KS.

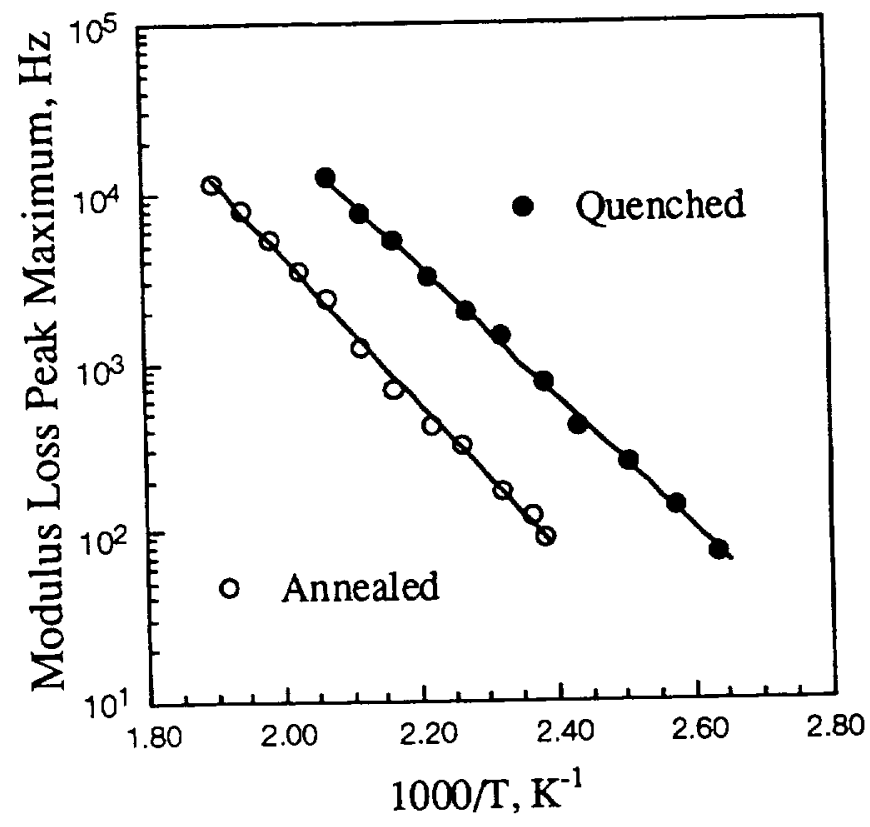

(d) $10 \mathrm{KS}$.

Figure 8.- Log of the modulus loss peak maximum plotted against $1 \pi$ for both the annealed and quenched glass samples. 


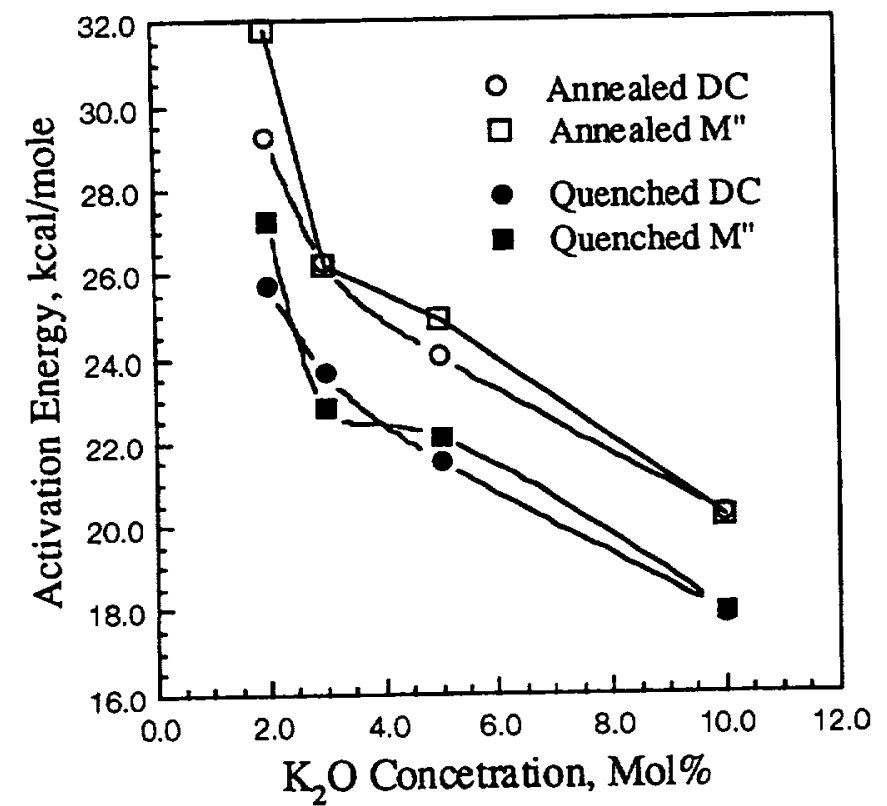

Figure $9 a .-D C$ and $M^{*}$ loss peak maximum activation energies for both annealed and quenched glass samples.

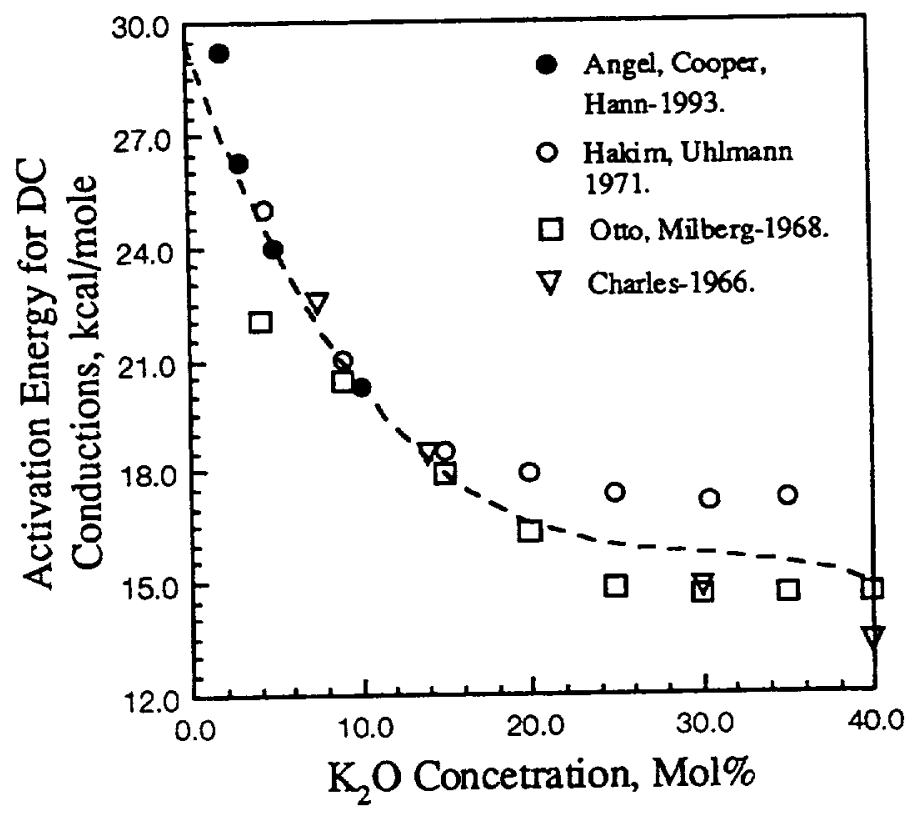

Figure $9 b .-D C$ conductivity activation energy values for annealed samples from this work plotted with values from previous works as a function of potassium oxide concentration. 


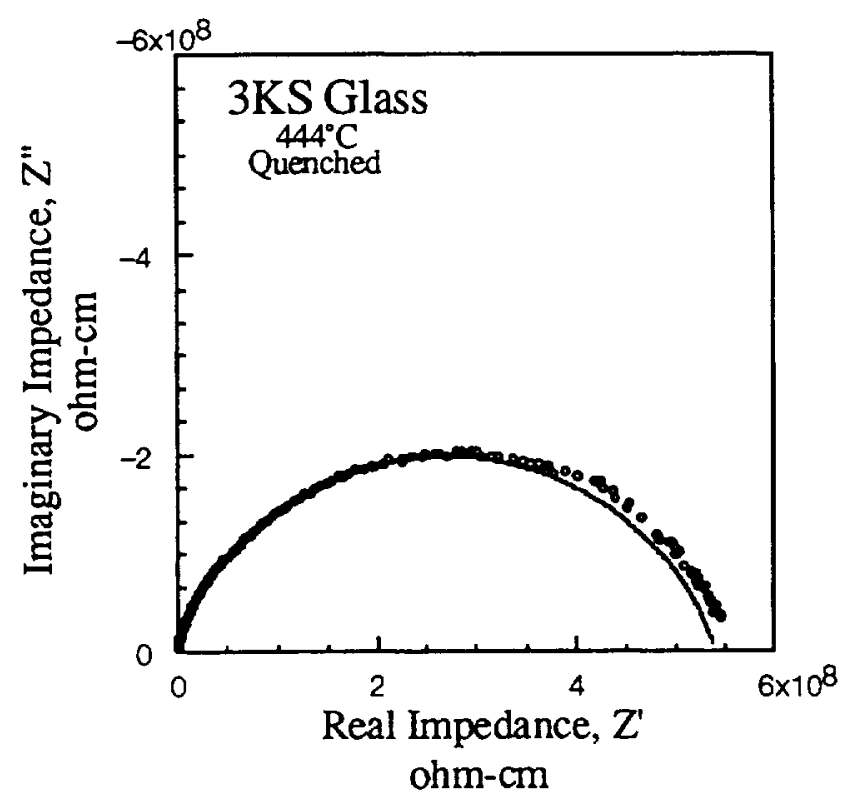

Figure 10.-Complex impedance plot of 3KS quenched sample at $444{ }^{\circ} \mathrm{C}$. Solid line corresponds to a least squares circular fit and the $x$ axis intercept is equal to the resistivity of the sample. 
Public reporting burden for this collection of intormation is estimated to average 1 hour per response, including the time for reviewing instructions, searching existing data sources, gathering and maintaining the data needed, and completing and reviewing the collection of information. Send comments regarding this burden estimate or any other aspect of this gathing Dection of intormation, including suggestons 22202-4302, and to the Office of Maragement and Budget, Paperwork Reduction Project (0704-0188). Wasthington, DC 20503.
1. AGENCY USE ONLY (Leave blank)
2. REPORT DATE
August 1993
3. REPORT TYPE AND DATES COVERED
Technical Memorandum

4. TITLE AND SUBTTILE

Thermal History Effects on Electrical Relaxation and Conductivity for

Potassium Silicate Glass With Low Alkali Concentrations

6. AUTHOR(S)

Paul W. Angel, Raiford E. Hann, and Alfred R. Cooper

\section{PERFORMING ORGAMIZATION MAME(S) AND ADDRESS(ES)}

National Aeronautics and Space Administration

Lewis Research Center

Cleveland, Ohio 44135-3191

WU-505-62-70

9. SPONSORING/MONTORING AGENCY NAME(S) AND ADDRESS(ES)

10. SPONSORINGMONITORING AGENCY REPORT NUMBER

National Aeronautics and Space Administration

Washington, D.C. 20546-0001

NASA TM-106324

\section{SUPPLEMENTARY NOTES}

Paul W. Angel and Raiford E. Hann, NASA Lewis Research Center, Cleveland, Ohio; and Alfred R. Cooper, Department of Materials Science and Engineering, Case Western Reserve University, Cleveland, Ohio 44106. Responsible person, Paul W. Angel, (216) 433-8008.

12a. DISTRIBUTION/AVALABILITY STATEMENT

12b. DISTRIBUTION CODE

Unclassified - Unlimited

Subject Category 27

\section{ABSTRACT (Maximum 200 words)}

Electrical response measurements from $10 \mathrm{~Hz}$ to $100 \mathrm{kHz}$ between $120^{\circ}$ and $540^{\circ} \mathrm{C}$ were made on potassium-silicate glasses with alkali oxide contents of 2, 3,5 and 10 mol\%. Low alkali content glasses were chosen in order to try to reduce the Coulombic interactions between alkali ions to the point that frozen structural effects from the glass could be observed. Conductivity and electrical relaxation responses for both annealed and quenched glasses of the same composition were compared. Lower DC conductivity $\left(\sigma_{D C}\right)$ activation energies were measured for the quenched compared to the annealed glasses. The two glasses with the lowest alkali contents exhibited a non-Arrhenius concave up curvature in the $\log \sigma_{\mathrm{DC}}$ against $1 / \mathrm{T}$ plots, which decreased upon quenching. A sharp decrease in $\sigma_{\mathrm{DC}}$ was observed for glasses containing $\mathrm{K}_{2} \mathrm{O}$ concentrations of 5 mol\% or less. The log modulus loss peak ( $\mathrm{M}^{\mathrm{n}}$ ) maximum frequency plots against $1 / \mathrm{T}$ all showed Arrhenius behavior for both annealed and quenched samples. The activation energies for these plots closely agreed with the $\sigma_{\mathrm{DC}}$ activation energies. A sharp increase in activation energy was observed for both series as the potassium oxide concentration decreased. Changes in the electrical response are attributed to structural effects due to different alkali concentrations. Differences between the annealed and quenched response are linked to a change in the distribution of activation energies (DAE).

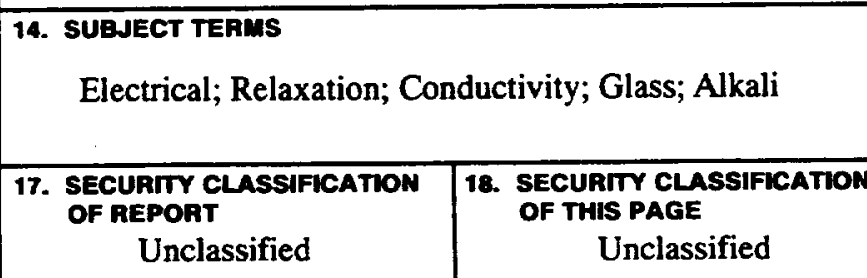

19. SECUATY CLASSIFICATION OF ABSTRACT Unclassified 21

16. PAICE CODE

$\mathrm{A} 03$ 